EDITORIAL

\title{
THE SCIENTIFIC AND TECHNOLOGICAL RESEARCH IN CHILE
}

Engineering consists of a set of applied disciplines that depend on science, not being themselves sciences. It is the duty of an engineer to develop technical solutions to practical problems. While doing so, he employs technology, often derived from science, but not being science itself.

Technology includes technical materials and methods to reach practical objectives. It is proper to expect and demand for solutions to practical problems from engineers. Our country has an almost null production of industrial patents, thus it turns out to be interesting to analyze the causes of this fact and the scarce technological development that we hold.

Studies performed about Chilean human resources have been coincident in characterizing some of the most relevant problems. These are:

- too few doctors formed,

- little applied research,

- low expenses in innovation and development,

- low contribution from industry to the above matters.

It may also be noted that the interesting scientific - technological production, as seen by the number of publications in specialized magazines, does not have the corresponding counterpart in the generation of industrial patents.

Jose Joaquín Brunner and Gregory Elacqua, researchers from Universidad Adolfo Ibáñez (Chile), claim that Chile not only invests a small percentage of its GIP in technological research, but it is also distributed in different way, as compared to industrialized countries. The contribution from industry is about $15 \%$ in Chile, while in the industrialized countries it is around $69 \%$.

Regarding academic work, $15 \%$ is dedicated to research and development activities. The figure is clearly insufficient; in our country there are only 12 individuals per ten thousand working people dedicated to technological - scientific work, whereas in industrialized countries the figure rises from 50 to 100 .

Since universities develop most of the academic work, their attention is centered in basic sciences and they do not work in practical application areas, thus basic sciences related doctorates are preferred by candidates. Industrialized countries have understood that it is the duty of universities to develop knowledge that may be applied to growth and economic development of the country. 
One of the higher education problems in Chile is the scarce formation of scientific and technological personnel having the degree of doctor (Ph.D). Chile is forming only four doctors per million of inhabitants, compared to eight in Mexico, eleven in Argentina and eighteen in Brazil. The goal in Chile, according to sources from ministry of Education, is to from by year 2010 from 500 to 600 doctors annually.

Improvement in these aspects, according to J.J. Bruner, requires a completely different postgraduate policy, that is to say, forming a great number of people dedicated to applied research and to develop doctorate programs in all of those areas where we need to improve the teaching and research quality, by means of teachers with better background in applied sciences.

Editor Committee 